\title{
Isolation of chicken vitellogenin I and III cDNAs and the developmental regulation of five estrogen-responsive genes in the embryonic liver
}

\author{
Marilyn I. Evans, Rosane Silva, ${ }^{1}$ and John B.E. Burch ${ }^{2}$ \\ Institute for Cancer Research, Fox Chase Cancer Center, Philadelphia, Pennsylvania 19111 USA
}

The isolation of cDNA clones that code for portions of the two minor chicken vitellogenin (VTG) genes (VTGI and VTGIII) is reported. These clones represent unique sequences that are expressed exclusively in the livers of estrogenized birds. In the liver of the egg-laying hen, the levels of RNAs encoding VTGI, VTGII, and VTGIII are approximately $11,000,30,000$, and 3,000 molecules per cell, respectively. We have used the newly isolated clones, as well as the yolk protein cDNAs previously available [VTGII, apolipoprotein II (apoVLDLII), and apolipoprotein B], as probes to examine several aspects of the regulation of these genes by estradiol. First, we demonstrate that the capacity of each gene to respond to estradiol is acquired between 8 and 13 days in ovo. The response of four of these genes to estradiol is diminshed during late fetal development, but the responsiveness is recovered within a week after hatching. Second, we demonstrate that these genes display distinct kinetic response profiles following the addition of estradiol. Third, as has been described previously for the VTGII and apoVLDLII genes, we demonstrate that a single injection of estradiol effects a long-term reprogramming event (hepatic memory) that allows a faster onset of the rapid accumulation of both VTGI and VTGIII RNAs following a subsequent rechallenge by estradiol. Collectively, these three sets of data suggest molecular parameters that may contribute to both the coordinate and noncoordinate regulation of this set of genes by estradiol.

[Key Words: Vitellogenin; apolipoprotein; yolk protein; regulation by estrogen; liver-specific gene expression; hepatic memory]

Received September 2, 1987; revised version accepted November 9, 1987.

The chicken yolk protein genes provide an excellent model system for studying tissue-specific, steroid-specific, and developmentally regulated programs of gene expression. The yolk proteins are coordinately synthesized in the livers of chickens (and other oviparous species) in response to the elevated circulating levels of estradiol, which also serve to coordinate the production of the egg-white proteins in the chicken oviduct (for reviews, see Chambon et al. 1984; Wahli and Ryffel 1985). The three vitellogenin (VTG) genes and the apolipoprotein II (apoVLDLII) gene are normally expressed only in hens during periods of egg laying (Wiskocil et al. 1980; Wang et al. 1983). ApoVLDLII appears unchanged in the egg yolk, whereas the VTG genes are processed proteolytically to yield mature yolk proteins. The precise precursor-product relationship between VTGII and three of

1On leave from Instituto de Biofisica, Universidade Federal do Rio de Janeiro, Brazil.

${ }^{2}$ Corresponding author. the yolk proteins has recently been resolved (van het Schip et al. 1987). Less is known of these relationships for the other two VTG genes (Deeley et al. 1975; Wang et al. 1983; Wallace and Morgan 1986). A fifth gene that contributes protein to the egg yolk is constitutively expressed in chickens of both sexes and codes for a protein, apolipoprotein $\mathrm{B}$ (apoB), that also serves as a component of circulating very-low-density and low-density lipoprotein particles (Evans and Burley 1987). The level of apoB RNA in the liver is increased about sixfold following the administration of estrogen (Kirchgessner et al. 1987).

Although the molecular mechanisms by which estrogen regulates these genes remain unknown, sequence comparisons between the $5^{\prime}$-flanking regions of the two previously cloned yolk protein genes (VTGII and apoVLDLII) have revealed a number of shared sequence motifs that could be involved in their coordinate transcriptional regulation (Burch 1984; van het Schip et al. 1986). In addition, the conserved dyad sequence GGTCANNNTGACC has recently been shown to be an 
essential part of the estrogen-response elements (EREs) associated with two frog VTG genes (Klein-Hitpass et al. 1986; Seiler-Tuyns et al. 1986), as well as the chicken VTGII gene (Burch et al. 1988). The significance of these and other DNA sequence elements to the coordinate regulation of the entire set of target genes awaits further functional analysis, as well as comparisons with additional liver-specific genes that are regulated by estrogen. The isolation of cDNA clones for the VTG genes/VTGI and VTGIII) reported in this study represents an important step toward this goal.

One intriguing aspect of the regulation of the estradiol-dependent induction of protein (Jost et al. 1973; Luskey et al. 1974; Capony and Williams 1980) and/or RNA (Gruber et al. 1976; Deeley et al. 1977; Jost et al. 1978 ) for the various yolk protein genes is the phenomenon of hepatic memory. This concept derives from the observation that there is a faster onset of rapid accumulation of both RNA and protein following a secondary administration of estrogen relative to that observed following the initial exposure to the hormone. In the present report we demonstrate that VTGI and VTGIII also display memory at the level of RNA. In fact, the VTGI gene displays the most pronounced memory effect of any of the chicken and frog yolk protein genes examined to date.

In addition to the memory response, the estrogen-induced expression of the yolk protein genes is subject to a number of developmental constraints. For example, Williams and co-workers demonstrated that the apoVLDLII gene will respond to estradiol earlier in development than the VTGII gene will (Elbrecht et al. 1984). Recently, we have shown that the yolk protein genes are also subject to developmental influences between 1 and 6 weeks after hatching (Evans et al. 1987). During both of these periods of development, the changes in expression of the yolk protein genes appear to be correlated with developmental changes in the level of estrogen receptors. In the present study we have extended these data further and demonstrate that there is a third distinct period of development just prior to hatching when the expression of the yolk protein genes is suppressed. Possible explanations for the decrease in estrogen responsiveness that characterizes this developmental period are discussed.

\section{Results and discussion}

The isolation of chicken VTGI and VTGIII clones from a cDNA library

We employed the strategy of differential screening as a means of isolating clones of genes that are responsive to estrogen in the avian liver. A $\lambda$ gt1 1 cDNA library (prepared from RNA that was isolated from the livers of egglaying hens) was screened sequentially with cDNA probes prepared from liver RNA of estradiol-stimulated and hormone-naive chickens. To identify and exclude clones of the two most abundant liver RNAs that are induced by estradiol, we added a mixture of unique-se- quence VTGII (Cozens et al. 1980) and apoVLDLII (Wiskocil et al. 1980) SP6-derived ${ }^{32}$ P-labeled RNA to the ${ }^{32} \mathrm{P}$-labeled cDNA that was prepared against hormonenaive liver RNA. In a primary screen of 4000 recombinant phage, 44 clones were identified that appeared to code for RNA species induced by estradiol. Three of these clones $(\lambda \mathrm{cV} 1-36, \lambda \mathrm{cV} 3-38$, and $\lambda \mathrm{cAB}-11)$ were plaque purified, and the inserts $(0.9,0.65$, and $0.7 \mathrm{~kb}$, respectively) were subcloned in both orientations into the EcoRI site of the plasmid vector SP65 for further analysis. The $\lambda \mathrm{CAB}-11$ clone was identified as coding for a portion of the apoB gene (Kirchgessner et al. 1987; T. Kirchgessner, pers. comm.)

The sense and antisense strands for pcV1-36 and pcV3-38 were determined by preparing labeled SP6 transcripts and hybridizing these to Northern blots of liver RNA isolated from hormone-naive and estradiol-stimulated birds. Data obtained using the antisense probes are shown in Figure 1 and corroborate that the RNA species homologous to pcV1-36 and pcV3-38 are induced de novo in the liver in response to estradiol. The data also indicate that the two probes hybridize to RNAs that are slightly larger (pcV1-36) and slightly smaller (pcV3-38) than the VTGII mRNA, which runs with an apparent molecular weight of $6.7 \mathrm{~kb}$ (Wieringa et al. 1978) and has 5787 bp by sequencing (van het Schip et al. 1987).

Hybrid-selected translation (see Materials and methods) was used to identify the pcV1-36 and pcV3-38 clones as VTGI and VTGIII. RNAs selected by hybridization to pcV1-36 and pcV3-38 were prepared and translated in vitro. As shown in Table 1, when total RNA from the livers of egg-laying hens was translated, the relative synthesis of the three VTG proteins (VTGI : VTGII : VTGIII, $3: 6: 1$ ) was similar to the reported in vivo ratio of $3: 10: 1$ in the chicken liver (Wang et al. 1983). Compared to the translation products of total RNA, the products derived from the pcVl-36 selected message were enriched in VTGI, and those derived from the pcV3-38 selected message were enriched in VTGIII. We conclude that pcV1-36 and pcV3-38 code for portions of VTGI and VTGIII, respectively.

The VTGI and VTGIII cDNA fragments each correspond to unique sequences in the chicken genome

Given the high degree of homology among the family of four frog VTG genes (Wahli and Ryffel 1985), we wondered whether the VTGI and VTGIII cDNA fragments might cross-react similarly, either with each other or with the VTGII gene. To address this, we prepared SP6derived RNA probes for VTGI and VTGIII and hybridized them under low stringency conditions (see Materials and methods) to Southern blots containing these fragments, as well as fragments covering the entire VTGII gene. The results of this analysis are shown in Figure 2. In each case, the probes are demonstrated to hybridize to their homologous fragments as expected. In contrast, the VTGI and VTGIII probes fail to hybridize to each other or to any portion of the VTGII gene. 


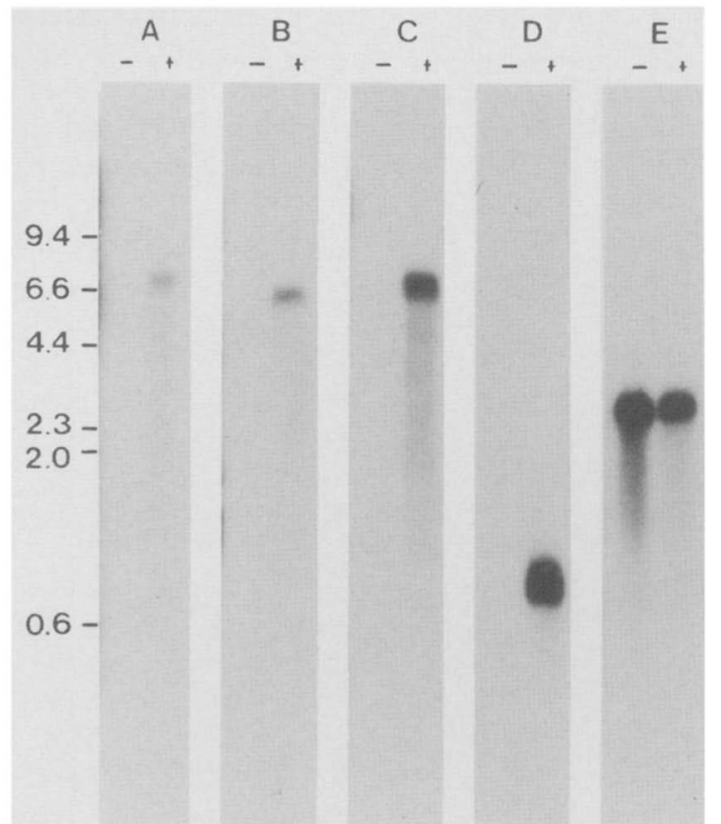

Figure 1. pcV1-36 and pcV3-38 correspond to large RNA species that are inducible by estradiol. Northern blots were prepared with RNA from hormone-naive $(-\mid$ and estrogenized $|+|$ liver and hybridized as described in Materials and methods. The probes used are pcVl-36 $(A), \mathrm{pcV} 3-38(B)$, VTGII $|C|$, apoVLDLII $|D|$, and chicken serum albumin $|E|$. The migration of HindIII fragments of $\lambda$ DNA are indicated in kilobases.

To determine whether VTGI and VTGIII themselves might be members of larger gene families unrelated to VTGII, we analyzed the complexity of each of our new cDNA probes by hybridizing them to genomic Southern blots. A parallel genomic blot was hybridized with a VTGII probe for comparison. The autoradiograms from this analysis are presented in Figure $3(\mathrm{~A}-\mathrm{C})$ (low stringency wash) and Figure 3 (D-F) (high stringency wash). It is clear that even under conditions of low stringency, the VTGI (Fig. 3A) and VTGIII (Fig. 3B) cDNA probes yield very simple hybridization patterns. The fact that only single bands are apparent in several lanes of each blot indicates that VTGI and VTGIII are very likely each single-copy genes (Fig. $3 \mathrm{D}$ and E, respectively). In con-

Table 1. Identification of clones for VTGI and VTGIII by hybrid selection, in vitro translation, and specific immunoprecipitation

\begin{tabular}{lcccc}
\hline & \multicolumn{3}{l}{ Immunoprecipitable counts $(\mathrm{cpm})$} & \\
\cline { 2 - 4 } $\begin{array}{l}\text { RNA } \\
\text { translated }\end{array}$ & $\begin{array}{l}\text { anti- } \\
\text { VTGI }\end{array}$ & $\begin{array}{l}\text { anti- } \\
\text { VTGII }\end{array}$ & $\begin{array}{l}\text { anti- } \\
\text { VTGIII }\end{array}$ & $\begin{array}{l}\text { I:II:III } \\
\text { ratio }\end{array}$ \\
\hline $\begin{array}{l}\text { Total } \\
\text { pcV1-36 } \\
\text { selected }\end{array}$ & 2850 & 6140 & 680 & $29: 64: 07$ \\
$\begin{array}{c}\text { pcV3-38 } \\
\text { selected }\end{array}$ & 1630 & 470 & 490 & $63: 18: 19$ \\
\hline
\end{tabular}

RNA was isolated from the livers of egg-laying hens and enriched for either pcV1-36 or pcV3-38 sequences by hybrid selection, as described in Materials and methods. trast, at least two genomic bands are apparent in each lane probed with the VTGII cDNA fragment (Fig. 3C, F). The complexity of this VTGII pattern cannot be explaned by the restriction map of the cloned VTGII gene, suggesting that there probably is a VTGII-related gene or pseudogene, as has been noted previously (Wilks et al. 1981). At present there is no evidence that this VTGIIrelated genomic sequence is either VTGI or VTGIII, but a definitive conclusion cannot be made until we achieve the isolation of complete sets of overlapping clones for the two minor VTG genes.

The three VTG genes are each expressed exclusively in the livers of estrogenized birds and all display hepatic memory at the RNA level

Whereas it has been demonstrated previously that the three chicken VTG proteins are synthesized and se-

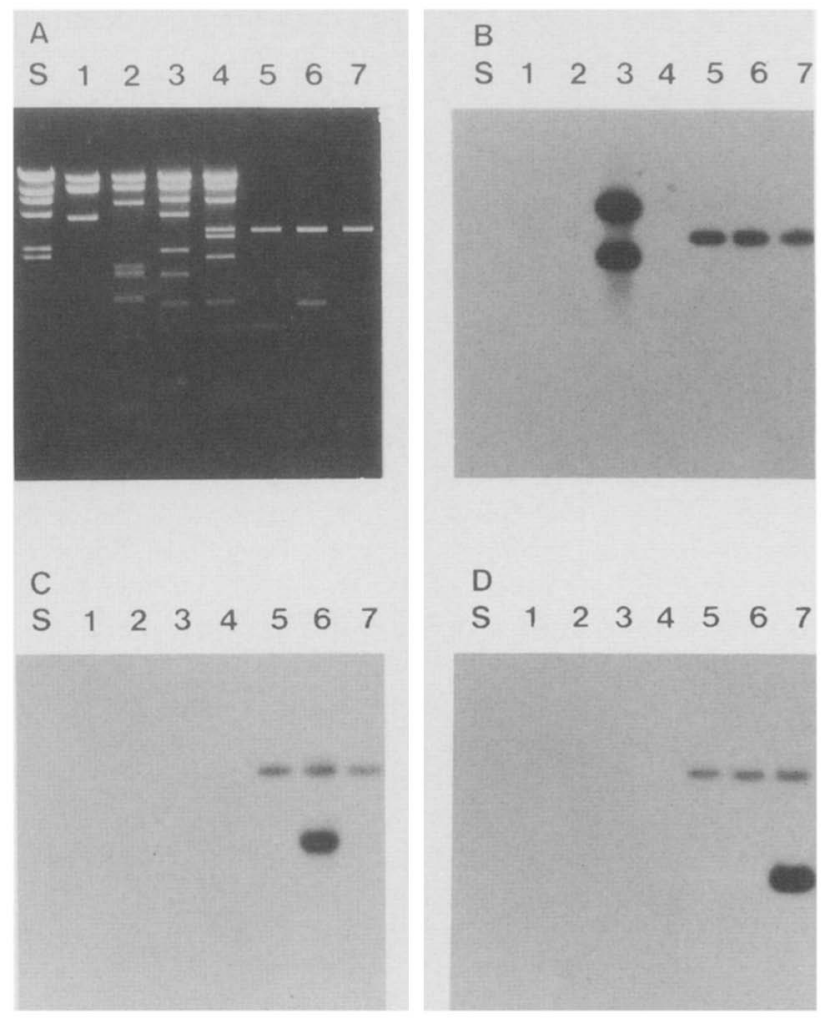

Figure 2. Cloned VTGI and VTGIII cDNA fragments lack homology with VTGII and apoVLDLII sequences. Cloned DNAs were digested with EcoRI and subjected to electrophoresis through $1 \%$ agarose gels. The lanes contain an entire apoVLDLII genomic clone (1), portions of the VTGII gene which, together, represent the entire VTGII gene $(2,3,4)$, an apoVLDLII cDNA clone in SP6 vector (5), a VTGI cDNA clone in SP6 vector (6), and a VTGIII cDNA clone in SP6 vector (7). (Lane S) HindIII fragments of $\lambda$ DNA, the sizes of which are indicated in Fig. 1. The gels were stained with ethidium bromide $(A)$, transferred, and hybridized (see Materials and methods) with SP6-derived antisense probes of VTGII $(B)$, VTGI $(C)$, and VTGIII $(D)$. The large fragment in lanes 5, 6, and 7 is the SP6 vector. The filters were washed for $1 \mathrm{hr}$ at low stringency $\left(2 \times \mathrm{SSC}, 0.1 \% \mathrm{SDS}, 25^{\circ} \mathrm{C}\right)$ and exposed to Kodak XAR film. 


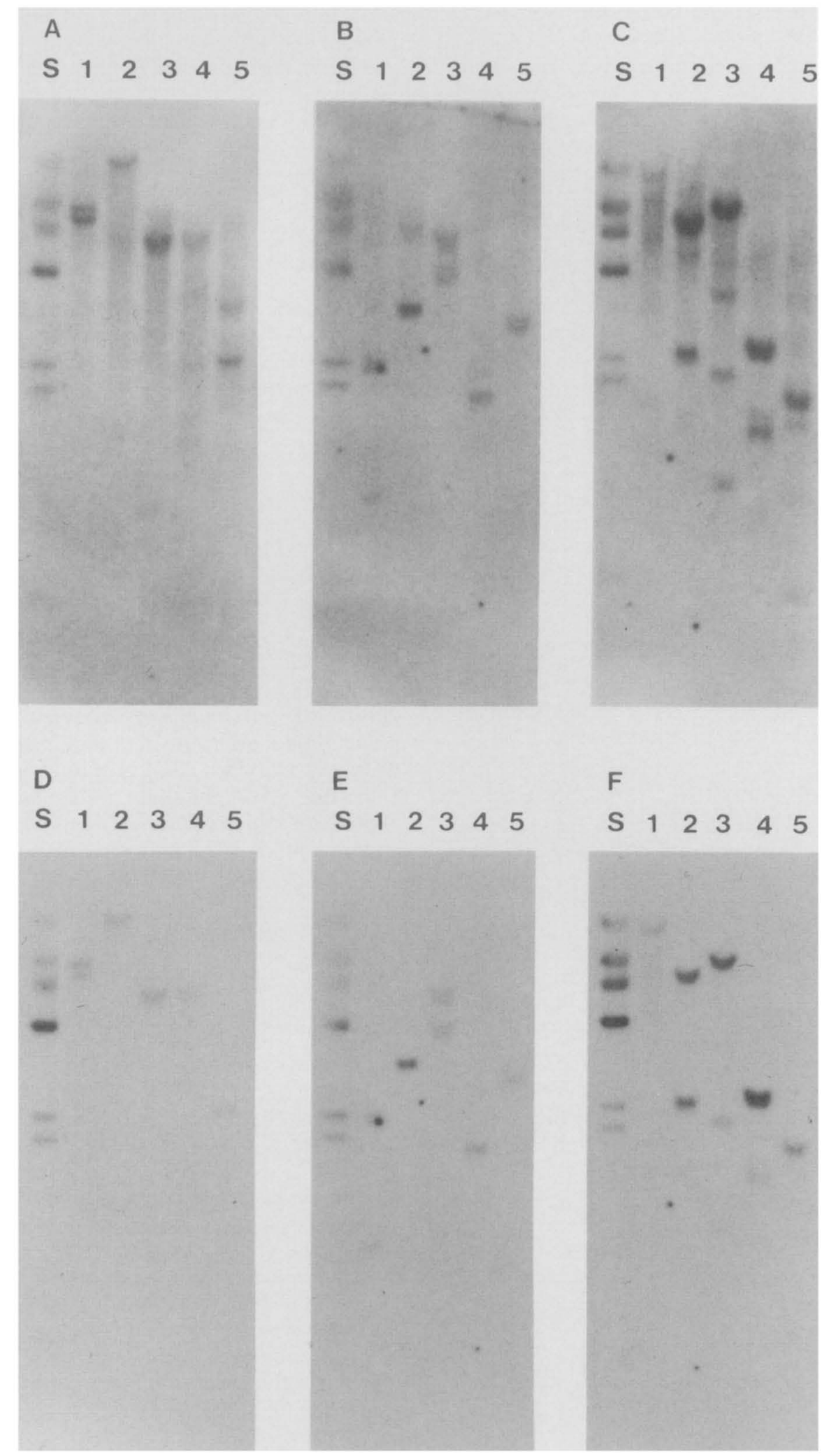

Figure 3. Cloned VTGI and VTGIII cDNA fragments appear to represent single-copy genes. Chicken genomic DNA was digested with BamHI (lane 1), EcoRI (lane 2), HindIII (lane 3), PstI (lane 4), and PvuII (lane 5). Southern blots were prepared as described in Materials and methods and hybridized with SP6-derived antisense probes of VTGI $(A, D)$, VTGIII $(B, E)$, and VTGII $(C, F)$. The filters were washed for $1 \mathrm{hr}$ at low stringency $\left(2 \times \operatorname{SSC}, 0.1 \% \operatorname{SDS}, 25^{\circ} \mathrm{C}\right)$, exposed to Kodak XAR film $(A-C)$, washed for 1 hr at high stringency $\left(0.1 \times \mathrm{SSC}, 0.1 \% \mathrm{SDS}, 65^{\circ} \mathrm{C}\right)$, and reexposed to film $(D-F)$. (Lane $\left.S\right)$ HindIII fragments of $\lambda$ DNA; their sizes are indicated in Fig. 1. 
creted from the liver in response to estradiol /Wang et al. 1983), it has not been determined whether the VTG genes are expressed in other tissues as well. To address this, the amounts of RNA coding for each of the three VTG genes were directly compared in a variety of tissues exposed to estradiol in vivo. RNA from hormone-naive liver was included among the samples as a reference. A probe for mouse $\alpha$-actin RNA (Minty et al. 1981) was used to indicate the amount of hybridizable RNA in each dot. Of the 10 tissues examined (Fig. 4), the only one that contains detectable amounts of VTG RNAs is the estrogen-stimulated liver. Overexposure of these blots indicates that if VTG RNAs are expressed in any of the other tissues, the levels must be less than $1 \%$ of those observed in liver (data not shown).

We quantitated the levels of the VTG RNAs in the livers of egg-laying hens by solution hybridization (see Materials and methods) and found that VTGII is expressed at approximately 30,000 molecules of RNA per cell. This estimate for the abundance of VTGII RNA falls between the two determinations reported previously (Gruber et al. 1976; Jost et al. 1978). Our results indicate that VTGI RNA is expressed at 11,000 molecules per cell and VTGIII RNA at 3,000 molecules per cell. Thus, the relative levels of VTGI : VTGII : VTGIII RNA in the liver of the laying hen are approximately $4: 10: 1$, respectively. These relative values are similar to the ratio of the VTG proteins synthesized in adult estrogenized roosters (Wang et al. 1983), indicating that there is no appreciable differential translational control among this set of coordinately regulated genes.

Hepatic memory has been described for the chicken VTGII (Deeley et al. 1977; Jost et al. 1978) and apoVLDLII (Codina-Salada et al. 1983) genes, as well as the four frog VTG genes (Wolffe and Tata 1983; Wahli and Ryffel 1985). To determine whether the VTGI and VTGIII genes also display hepatic memory at the level of RNA, we examined the kinetics of the accumulation of

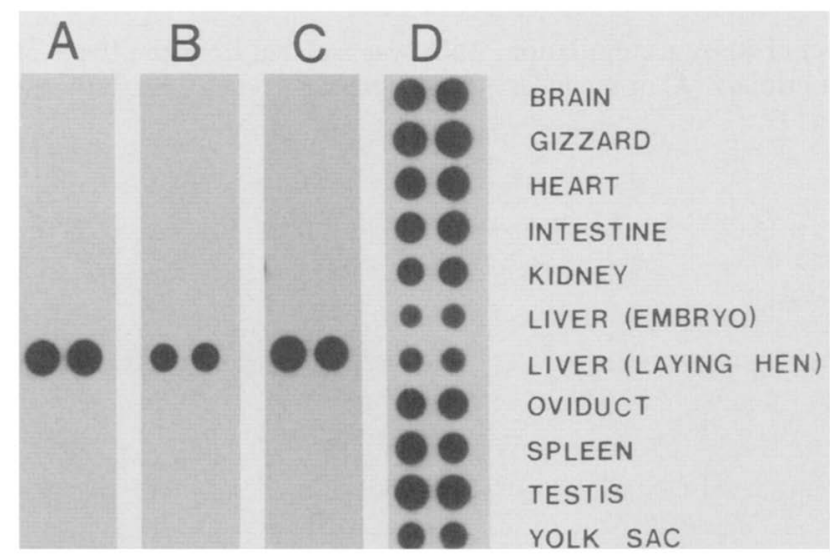

Figure 4. Expression of the three VTG genes is restricted to the liver of estrogenized birds. RNA was isolated from various tissues, as described in Materials and methods, dotted onto nitrocellulose, and hybridized with SP6-derived probes for VTGI $(A)$, VTGIII $(B)$, VTGII $(C)$, and mouse $\alpha$-actin $(D)$.
VTGI and VTGIII RNA following the administration of primary and secondary injections of estradiol to l-weekold birds. Figure 5 shows that both VTGI and VTGIII display lag times for the onset of rapid accumulation of RNA following a primary exposure to estradiol and that these lag times are reduced in a secondary response. Interestingly, whereas the primary and secondary lags observed prior to the rapid accumulation of VTGIII RNA (Fig. $5 \mathrm{~B}$ ) are very similar to those described previously for VTGII (Jost et al. 1978; Evans et al. 1987), the lag times for VTGI (Fig. 5A) are significantly longer.

It is also worth noting that the maximal level of VTGIII RNA in these week-old birds is only half that observed in laying hens. For VTGI, the difference is even greater, with the maximal level of VTGI RNA at this age reaching less than one-fifth the level achieved in the fully mature birds. The relationship between such agedependent differences in the expression of the various yolk protein genes and developmental changes in the expression of the estrogen receptor is described in detail elsewhere (Evans et al. 1987).

\section{Estradiol-induced expression of five target genes during liver ontogeny}

It has been reported previously that the expression of the apoVLDLII gene can be induced by estradiol in the liver earlier in development than that of the VTGII gene (Elbrecht et al. 1984). To determine the inducibility of the other two VTG genes prior to hatching, we injected estradiol into embryos on different days of development and assayed for the induction of specific yolk protein gene RNAs later (see Materials and methods). The estradiol-induced expression measured for each of five target genes examined as a function of development is shown in Figure 6. It is apparent from these data that the estrogen responsiveness of the individual yolk genes is achieved at different times during the development of the liver. The apoB gene, whose expression is increased approximately sixfold in response to estradiol /Kirchgessner et al. 1987; M.I. Evans et al., unpubl.), can be maximally expressed as early as day 9 of embryonic development (12 days prior to hatching). Although not maximal, apoVLDLII RNA is also readily detected in response to estradiol at day 9, whereas the three VTG genes are barely inducible at this stage. The estrogen-induced expression of apoVLDLII and the three VTG genes increases progressively for the next 4-6 days, in agreement with the apoVLDLII and VTGII results of Williams and co-workers (Elbrecht et al. 1984). These data are reminiscent of the developmental regulation of the estrogen-dependent expression of the four frog VTG RNAs that accumulate at different rates and to different extents during different stages of development $(\mathrm{Ng}$ et al. 1984). The observed increase in the levels of chicken yolk gene RNAs coincides with a prehatching period of increasing levels of estrogen receptors (Gschwendt and Kittstein 1977; Elbrecht et al. 1984).

With respect to the ease with which these genes can first be activated as a function of development, the five 

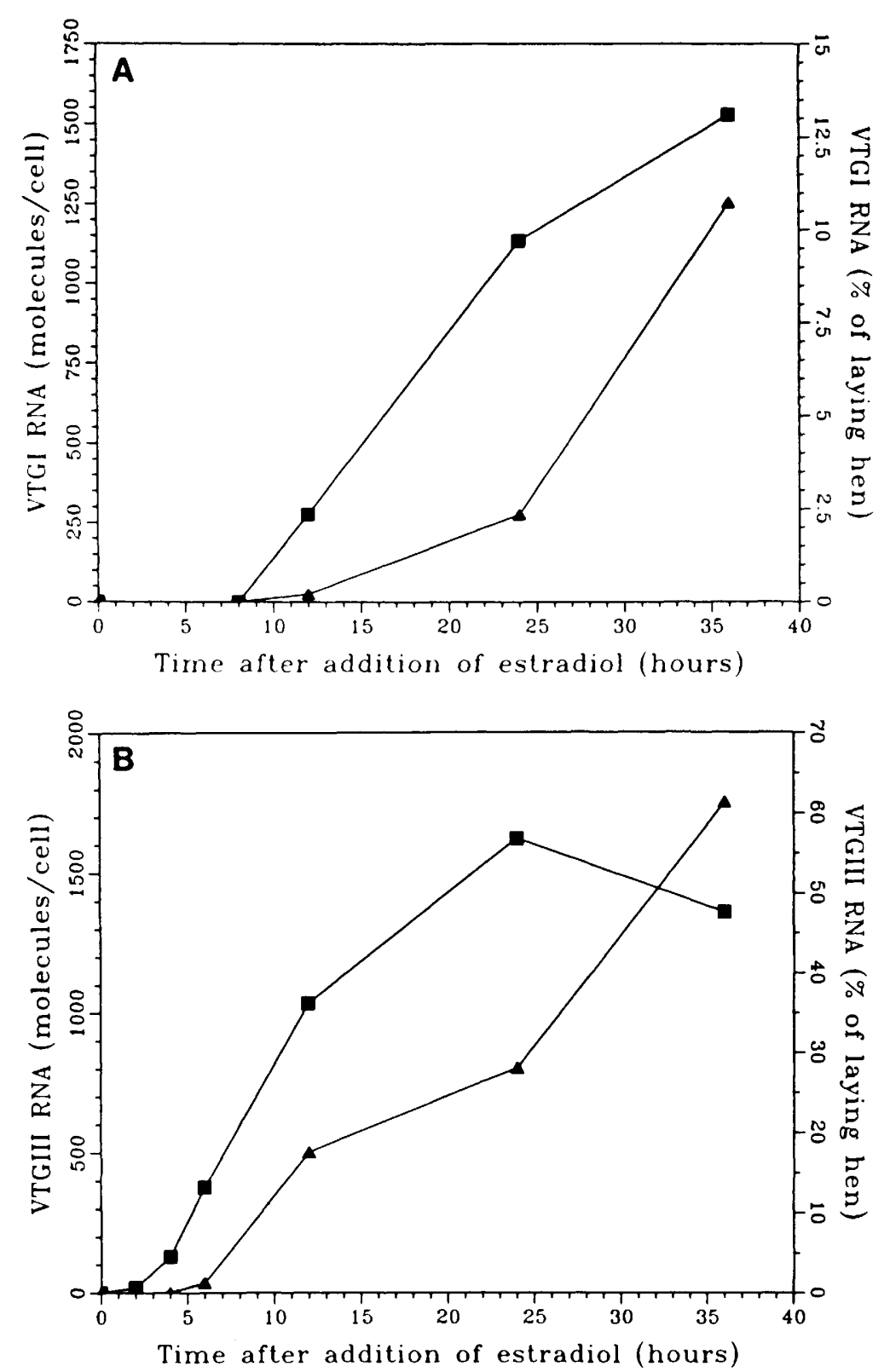

Figure 5. Both VTGI and VTGIII display hepatic memory at the level of RNA accumulation. RNA was isolated from the livers of 1 -week-old birds that were sacrificed at the times indicated following primary $(\boldsymbol{\Delta})$ or secondary $(\boldsymbol{\Pi})$ administration of $20 \mathrm{mg} / \mathrm{kg} 17-\beta$ estradiol. The RNA was dotted onto nitrocellulose and hybridized with SP6-derived antisense probes for VTGI $(A)$ and VTGIII $(B)$. The data were quantitated as described in Materials and methods.

genes are ordered in the following way: apoB $>$ apoVLDLII $>$ VTGIII $>$ VTGII $=$ VTGI. Interestingly, a similar order is apparent with respect to the time in development at which these genes gain the capacity to be maximally expressed in response to estradiol. For the three VTG genes, this occurs during the period between 1 and 6 weeks after hatching and coincides with a period when the maximal level of nuclear estrogen receptors increases from 1500 to 5000 sites per hepatocyte (Evans et al. 1987). As a working model, we suggest that the ordering of the individual genes with respect to estrogen responsiveness may reflect differences in the abilities of the respective receptor binding site(s) to productively bind activated estrogen receptors.
What then might determine how efficiently a gene is able to respond to activated estrogen receptors? The recent delineation and characterization of the EREs associated with three different VTG genes (two from the frog and one from the chicken) may provide some hints as to how variable estrogen responsiveness could be encoded. Although extensive data are not yet available, it seems reasonable that variations within the ERE core sequence (GGTCANNNTGACC) might affect the ability of the respective EREs to bind receptors and/or effect transcriptional activation. Additionally, the particular sequence context in which this 13-bp element resides, the distance of this element from the promoter, and the number of functional elements can each clearly influ- 


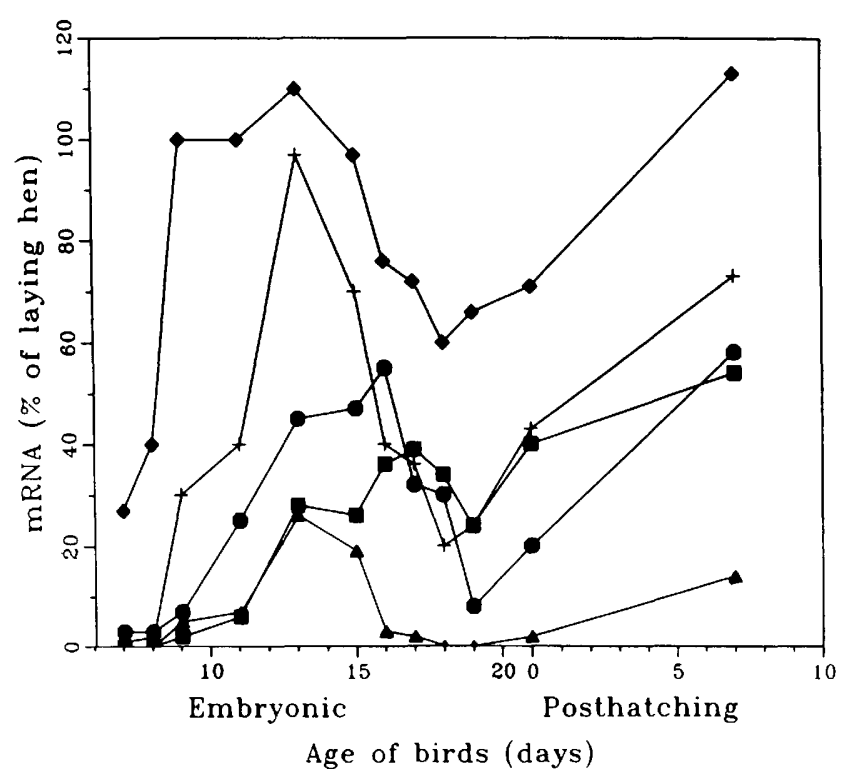

Figure 6. Acquisition of estrogen responsiveness for five yolk protein genes during embryonic development. RNA was isolated from the livers of embryos and hatchlings that were sacrificed $48 \mathrm{hr}$ after a single injection of $17-\beta$-estradiol. Following hybridization with SP6-derived antisense probes to VTGI $(\mathbf{\Delta})$, $\operatorname{VTGII}(\bullet)$, VTGIII $(\bullet)$, apoVLDLII $|+|$, and apoB $(\bullet)$, the specific RNAs were quantitated as described in Materials and methods.

ence the efficiency with which the EREs can enhance transcription in transient expression assays (Klein-Hitpass et al. 1986; Seiler-Tuyns et al. 1986; Burch et al. 1988).

Based on our analysis of the kinetics of the accumulation of RNA of the five major yolk protein genes, it is striking that the order in which the yolk protein genes are activated following a single injection estradiol (Fig. 5; Jost et al. 1978; Wiskocil et al. 1980; Evans et al. 1987) is similar to the order in which the respective genes can be expressed in response to estradiol during development (Fig. 6; Evans et al. 1987). Whereas the latter ordering could be related to the efficiency with which each gene can be expressed in response to a particular level of nuclear estrogen receptors (see above), the lag times involved prior to the onset of expression of the respective genes do not correlate with changing receptor levels. We have shown previously that in the livers of 1 -week-old birds (the age used in these experiments), the level of nuclear receptors becomes maximal within an hour of the administration of estradiol (Evans et al. 1987). In contrast, the rapid accumulation of yolk protein RNA commences 4 (apoVLDLII) to $20 \mathrm{hr}$ (VTGI) after a primary injection of estradiol. Moreover, whereas the kinetics of the accumulation of RNA are more rapid following a secondary presentation of estradiol for each of the four yolk protein genes that are induced de novo in response to estradiol, the kinetics of the accumulation of nuclear estrogen receptors are the same following primary and secondary injections of estradiol (Evans et al. 1987).

Whatever the basis is for the different lag times be- tween the addition of estradiol and the rapid accumulation of the respective yolk protein RNAs, we think it is significant that these ordered differences are apparent in both primary and secondary responses to estradiol (Fig. $5)$. We speculate that the differences in secondary response profiles may reflect inherent DNA sequence differences in the respective cis-regulatory regions associated with each gene (see above). Epigenetic events (e.g., changes in chromatin structure) may then be superimposed on these different primary DNA sequences to account for the slower initial responses to estradiol. Alternatively, critical changes in the activities and/or availabilities of trans-acting factors could be brought about as a consequence of the initial exposure to estradiol, and this may be relevant to memory.

In addition to the two periods of development noted above in which the expression of the yolk protein genes increases, we have identified a third period of development in which a striking dissimilarity in expression of the individual yolk protein genes is evident. This occurs during the late embryonic period when estradiol-induced expression is diminished for four of the five genes examined (Fig. 6). Whereas this is the first study of VTGI and VTGIII expression during late fetal development, other labs previously examined apoB, apoVLDII, and VTGII expression at the protein level during this period of development (Nadin-Davis et al. 1980; Elbrecht et al. 1981). Curiously, whereas the RNA and protein synthesis data appear to be qualitatively similar for both the VTGII and apoVLDII genes, the $40 \%$ decrease that we observe in apoB RNA expression is not reflected by a comparable decrease in apoB protein synthesis. The basis for this difference is not apparent. Although a comparable phenomenon has not been observed during normal frog development, Tata and co-workers have shown that the expression of the frog VTG genes is transiently depressed when liver cells are placed into culture. They also demonstrated that this result can be mimicked by heat shock and that nuclear estrogen receptor levels are reduced as part of a general stress response (Wolffe et al. 1984). The depression in the expression of the chicken yolk protein genes that we observe occurs during a period when the embryos are very likely subject to the stress of anoxia. However, since receptor levels do not decrease during this period of development (Lazier 1978) additional complexities are suggested. This is also indicated by the observation that the VTGII gene is much less refractile than the other yolk protein genes. Further experiments will be required to deduce the basis for the observations.

\section{Materials and methods}

\section{Isolation of cDNA clones}

A $\lambda$ gt11 cDNA library prepared from the livers of egg-laying hens (kindly provided by Todd Kirchgessner, UCLA) was screened according to the procedure of Huynh et al. (1985). Plaques were purified (Maniatis et al. 1982), and the inserts were subcloned into the EcoRI site of an SP65 vector (Promega Biotech). 


\section{Southern blots}

Ten micrograms of chicken genomic DNA or $1 \mu \mathrm{g}$ of cloned DNA was digested with restriction enzymes, separated by electrophoresis through $1 \%$ agarose gels, and transferred to Nytran membranes (S\&S). The blots were prehybridized, as described by Meinkoth and Wahl (1984), for $2 \mathrm{hr}$ at $42^{\circ} \mathrm{C}$ and hybridized with SP6-derived antisense RNA transcripts (Melton et al. 1984 ) for $16 \mathrm{hr}$ at $42^{\circ} \mathrm{C}$ followed by $16 \mathrm{hr}$ at $37^{\circ} \mathrm{C}$. SDS (1\%) was added to all hybridization solutions. The blots were washed as described in the figure legends.

\section{Northern blots}

RNA was prepared using the guanidinium/cesium method of Chirgwin et al. (1979). Total RNA (300 ng/lane) was separated by electrophoresis through $0.7 \%$ agarose/formaldehyde gels and transferred to Nytran membranes.

\section{Hybrid selection, in vitro translation, and immunoprecipitation}

Total RNA was isolated from the livers of egg-laying hens and hybrid-selected as described (Neilsen et al. 1985). In vitro translations were carried out using a reticulocyte lysate kit (Amersham) according to the directions therein. The translation products were incubated with preimmune rabbit serum at $22^{\circ} \mathrm{C}$ for $2 \mathrm{hr}$, staphylococcus protein A was added and the incubation was continued for 2 additional hr at $22^{\circ} \mathrm{C}$. The preimmune complexes were removed by centrifugation, then specific antibodies were added to the supernatant and incubated for $16 \mathrm{hr}$ at $4^{\circ} \mathrm{C}$. The immune complexes were precipitated with protein A-Sepharose beads for $2 \mathrm{hr}$ at $22^{\circ} \mathrm{C}$ and centrifuged. The pellets were washed 3 times in buffer $\mid 1 \%$ Triton X-100, 0.1\% SDS, 15 $\mathrm{mm}$ Tris at $\mathrm{pH} 7.5,120 \mathrm{~mm} \mathrm{NaCl}, 2$ mM EGTA, 2 mM EDTA, $0.1 \mathrm{~mm}$ dithiothreitol (DTT)] filtered, and counted. Antibodies to VTGI, VTGII, and VTGIII were a gift from Dr. David Williams (SUNY, Stony Brook).

\section{Quantitation of RNA}

RNA was applied to nitrocellulose filters and hybridized as described (Burch and Evans 1986), using 300 ng total RNA per dot for quantitation of the yolk RNAs. Serial dilutions of RNA prepared from the livers of egg-laying hens were included on each filter for reference. The molecules per cell of VTGI, VTGII, and VTGIII RNAs were quantitated by solution hybridization (Evans et al. 1981), using cold sense SP6 transcripts for standards and assuming $6.25 \mathrm{pg}$ total RNA per cell (Evans et al. 1987).

\section{Animals and hormone treatment}

Fertilized eggs from a white leghorn breeding flock were obtained from Truslow Farms (Chester, Maryland). Eggs were injected with $1 \mathrm{mg}$ of $17-\beta$-estradiol dissolved in propylene glycol (Burch and Weintraub 1983), and the livers were dissected at the times indicated in the figures. For the analysis of primary responses in young birds, untreated eggs were allowed to hatch, and the birds were injected with $20 \mathrm{mg} / \mathrm{kg} 17-\beta$-estradiol prior to sacrifice at the times indicated. For the analysis of secondary responses, the eggs were injected with $1 \mathrm{mg}$ of $17-\beta$-estradiol on day 12 of embryonic development and allowed to hatch, and the birds wre subsequently injected with $20 \mathrm{mg} / \mathrm{kg}$ of $17-\beta$-estradiol as indicated. For each time point, pieces of liver from three birds were pooled for the isolation of RNA, and the analysis was done in duplicate. To provide tissues for the preparation of
RNA for analysis of the tissue distribution of yolk RNAs, a 3week-old bird, hatched from an estrogen-treated egg, was given daily injections $(20 \mathrm{mg} / \mathrm{kg})$ of $17-\beta$-estradiol for 3 days, sacrificed, and dissected. The yolk sac was dissected from a 5-dayold embryo.

\section{Acknowledgments}

We thank Patrick J. O'Malley for excellent technical assistance; Dr. David L. Williams (SUNY, Stony Brook) for generously supplying antisera to VTGI, VTGII, and VTGIII; Todd Kirchgessner (UCLA) for kindly providing the chicken liver cDNA library and positively identifying the apoB clone; and Drs. Jesse Summers and John Pehrson for critical reading of the manuscript. This work was supported by National Institutes of Health grants GM 35535 (J.B.), CA 06927, and RR 05539, National Cancer Institute training grant CA-09035 (M.E.), the Brazilian Government through Universidade Federal do Rio de Janeiro, Brazil (R.S.), and an appropriation from the Commonwealth of Pennsylvania.

\section{References}

Burch, J.B.E. 1984. Identification and sequence analysis of the 5' end of the major chicken vitellogenin gene. Nucleic Acids Res. 12: 1117-1135.

Burch, J.B.E. and M.I. Evans. 1986. Chromatin structural transitions and the phenomenon of vitellogenin gene memory in chickens. Mol. Cell. Biol. 6: 1886-1893.

Burch, J.B.E., M.I. Evans, T.M. Friedman, and P.J. O'Malley. 1988. Two functional estrogen response elements are located upstream of the major chicken vitellogenin gene. Mol. Cell. Biol., (in press).

Burch, I.B.E. and H. Weintraub. 1983. Temporal order of chromatin structural changes associated with activation of the major chicken vitellogenin gene. Cell 33: 65-76.

Capony, F. and D.L. Williams. 1980. Apolipoprotein B of avian very low density lipoprotein: Characteristics of its regulation in nonstimulated and estrogen-stimulated rooster. Biochemistry 19: 2219-2226.

Chambon, P., A. Dierich, M.-P. Gaub, S. Jakowlev, J. Jongstra, A. Krust, J.-P. Lepennec, P. Oudet, and T. Reudelhuber. 1984. Promoter elements of genes coding for proteins and modulation of transcription by estrogens and progesterone. Rec. Prog. Horm. Res. 40: 1-42.

Chirgwin, J.M., A.E. Przybyla, R.J. MacDonald, and W.J. Rutter. 1979. Isolation of biologically active ribonucleic acid from sources enriched in ribonuclease. Biochemistry 18: 5294 5299.

Codina-Salada, J., J.P. Moore, and L. Chan. 1983. Kinetics of primary and secondary stimulation of the mRNA for apoVLDL-II, a major yolk protein, in the cockerel liver by estrogen. Endocrinology 113: 1158-1160.

Cozens, P.J., A.C.B. Cato, and J.-P. Jost. 1980. Characterization of cloned complementary DNA covering more than 6000 nucleotides $(97 \%)$ of avian vitellogenin mRNA. Eur. J. Biochem. 112: 443-450.

Deeley, R.G., D.S. Udell, A.T.H. Burns, J.I. Gordon, and R.F. Goldberger. 1977. Kinetics of avian vitellogenin messenger RNA induction. J. Biol. Chem. 252: 7913-7915.

Deeley, R.G., K.P. Mullinix, W. Wetekam, H.M. Kronenberg, M. Meyers, J.D. Eldridge, and R.F. Goldberger. 1975. Vitellogenin sythesis in the avian liver. Vitellogenin is the precursor of the egg yolk phosphoproteins. I. Biol. Chem. 250: 9060-9066.

Elbrecht, A., C.B. Lazier, A.A. Protter, and D.L. Williams. 1984. 
Independent developmental programs for two estrogen-related genes. Science 225: 639-641.

Elbrecht, A., D.L. Williams, M.-L. Blue, and C.B. Lazier. 1981. Differential ontogeny of estrogen responsiveness in the chick embryo liver. Can. 1. Biochem. 59: 606-612.

Evans, A.J. and R.W. Burley. 1987. Proteolysis of apoprotein B during the transfer of very low density lipoprotein from hen's blood to egg yolk. J. Biol. Chem. 262: 501-504.

Evans, M.I., L.J. Hager, and G.S. McKnight. 1981. A somatomedin-like peptide hormone is required during the estrogen-mediated induction of ovalbumin gene transcription. Cell 25: 187-193.

Evans, M.I., P.J. O'Malley, A. Krust, and J.B.E. Burch. 1987. Developmental regulation of the estrogen receptor and the estrogen responsiveness of five yolk protein genes in the avian liver. Proc. Natl. Acad. Sci. 84: 8493-8497.

Gruber, M., E.S. Bos, and G. AB. 1976. Hormonal control of vitellogenin synthesis in avian liver. Mol. Cell. Endocrinol. 5: $41-50$.

Gschwendt, M. and W. Kittstein. 1977. A cytoplasmic high affinity estrogen binding protein in the embryonic chicken liver. Eur. I. Biochem. 80: 461-468.

Huynh, T.V., R.A. Young, and R.W. Davis. 1985. Constructing and screening cDNA libraries in $\lambda \mathrm{gt} 10$ and $\lambda \mathrm{gt} 11$. In DNA cloning techniques: A practical approach (ed. D.M. Glover), vol. 1, pp. 49-78. IRL Press, Oxford and Washington, D.C.

Jost, J.-P., R. Keller, and C. Dierks-Ventling. 1973. Deoxyribonucleic acid and ribonucleic acid synthesis during phosvitin induction by $17 \beta$-estradiol in immature chicks. $/$. Biol. Chem. 248: 5262-5266.

Jost, J.-P., T. Ohno, S. Panyim, and A.R. Schuerch. 1978. Appearance of vitellogenin mRNA sequences and rate of vitellogenin synthesis in chicken liver following primary and secondary stimulation by $17 \beta$-estradiol. Eur. I. Biochem. 84: 355-361.

Kirchgessner, T.G., C. Heinzmann, K.L. Svenson, D.A. Gordon, M. Nicosia, H.G. Lebherz, A.J. Lusis, and D.L. Williams. 1987. Regulation of chicken apolipoprotein B: Cloning, tissue distribution, and estrogen induction of mRNA. Gene (in press).

Klein-Hitpass, L., M. Schorpp, U. Wagner, and G.U. Ryffel. 1986. An estrogen-responsive element derived from the $5^{\prime}$ flanking region of the Xenopus vitellogenin A2 gene functions in transfected human cells. Cell 46: 1053-1061.

Lazier, C.B. 1978. Ontogeny of the vitellogenic response to Oestradiol and of the soluble nuclear oestrogen receptor in embryonic-chick liver. Biochem. J. 174: 143-152.

Luskey, K.L., M.S. Brown, and J.L. Goldstein. 1974. Stimulation of the synthesis of very low density lipoproteins in rooster liver by estradiol. J. Biol. Chem. 249: 5939-5947.

Maniatis, T., E.F. Fritsch, and J. Sambrook. 1982. Molecular cloning. A laboratory manual. Cold Spring Harbor Laboratory, Cold Spring Harbor, New York.

Meinkoth, J. and G. Wahl. 1984. Hybridization of nucleic acids immobilized on solid supports. Anal. Biochem. 138: 267284.

Melton, D.A., P.A. Krieg, M.R. Rebagliati, T. Maniatis, K. Zinn, and M.R. Green. 1984. Efficient in vitro synthesis of biologically active RNA and RNA hybridization probes from plasmids containing a bacteriophage SP6 promoter. Nucleic Acids Res. 12: 7035-7056.

Minty, A.J., M. Caravatti, B. Robert, A. Cohen, P. Daubas, A. Weydert, F. Gros, and M.E. Buckingham. 1981. Mouse actin messenger RNAs. Construction and characterization of a recombinant plasmid molecule containing a complementary DNA transcript of mouse $\alpha$-actin mRNA. I. Biol. Chem. 256: $1008-1014$.
Nadin-Davis, S.A., C.B. Lazier, F. Capony, and D.L. Williams. 1980. Synthesis of apoprotein B of very low density lipoprotein in embryonic chick liver. Biochem. J. 192: 733-740.

Neilsen, P.J., G.K. McMaster, and H. Trachsel. 1985. Cloning of eukaryotic protein synthesis initiation factor genes: Isolation and characterization of cDNA clones encoding factor eIF-4A. Nucleic Acids Res. 13: 6867-6880.

$\mathrm{Ng}$, W.C., A.P. Wolffe, and J.R. Tata. 1984. Unequal activation by estrogen of individual Xenopus vitellogenin genes during development. Dev. Biol. 102: 238-247.

Seiler-Tuyns, A., P. Walder, E. Martinez, A.-M. Mérillat, F. Givel, and W. Wahli. 1986. Identification of estrogen-responsive DNA sequences by transient expression experiments in a human breast cancer cell line. Nucleic Acids Res. 14: $8755-8770$.

van het Schip, F., R. Strijker, J. Samallo, M. Gruber, and G. AB. 1986. Conserved sequence motifs upstream from the co-ordinately expressed vitellogenin and apoVLDLII genes of chicken. Nucleic Acids Res. 14: 8669-8680.

van het Schip, F.D., J. Samallo, J. Broos, J. Ophuis, M. Mojet, M. Gruber, and G. AB. 1987. Nucleotide sequence of a chicken vitellogenin gene and derived amino acid sequence of the encoded yolk precursor protein. I. Mol. Biol. 196: 245-260.

Wahli, W. and G.U. Ryffel. 1985. Xenopus vitellogenin genes. In Oxford surveys on eukaryotic genes (ed. N. MacLean), vol. 2, pp. 95-120. Oxford University Press, Oxford.

Wallace, R.A. and J.P. Morgan. 1986. Isolation of phosvitin: Retention of small molecular weight species and staining characteristics on electrophoretic gels. Anal. Biochem. 157: 256-261.

Wang, S., D.E. Smith, and D.L. Williams. 1983. Purification of avian vitellogenin III: Comparison with vitellogenins I and II. Biochemistry 22: 6206-6212.

Wieringa, B., J. Mulder, A. van der Ende, A. Bruggeman, G. AB, and M. Gruber. 1978. Purification of vitellogenin mRNA and serum albumin mRNA from avian liver by preparative gel electrophoresis. Eur. I. Biochem. 89: 67-79.

Wilks, A., A.C.B. Cato, P.J. Cozens, I.W. Mattaj, and J.-P. Jost. 1981. Isolation and fine structure organisation of an avian vitellogenin gene coding for the major estrogen-inducible mRNA. Gene 16: 249-259.

Wiskocil, R., P. Bensky, W. Dower, R.F. Goldberger, J.I. Gordon, and R.G. Deeley. 1980. Coordinate regulation of two estrogen-dependent genes in avian liver. Proc. Natl. Acad. Sci. 77: 4474-4478.

Wolffe, A.P. and J.R. Tata. 1983. Coordinate and non coordinate estrogen-induced expression of $\mathrm{A}$ and $\mathrm{B}$ groups of vitellogenin genes in male and female Xenopus hepatocytes in culture. Eur. J. Biochem. 130: 365-372.

Wolffe, A.P., A.J. Perlman, and J.R. Tata. 1984. Transient paralysis by heat shock of hormonal regulation of gene expression. EMBO I. 3: 2763-2770. 


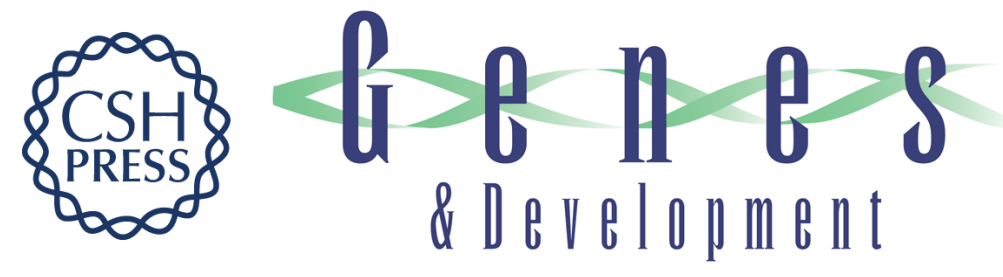

\section{Isolation of chicken vitellogenin I and III cDNAs and the developmental regulation of five estrogen-responsive genes in the embryonic liver.}

M I Evans, R Silva and J B Burch

Genes Dev. 1988, 2:

Access the most recent version at doi:10.1101/gad.2.1.116

References This article cites 38 articles, 12 of which can be accessed free at: http://genesdev.cshlp.org/content/2/1/116.full.html\#ref-list-1

License

Email Alerting

Receive free email alerts when new articles cite this article - sign up in the box at the top Service right corner of the article or click here.

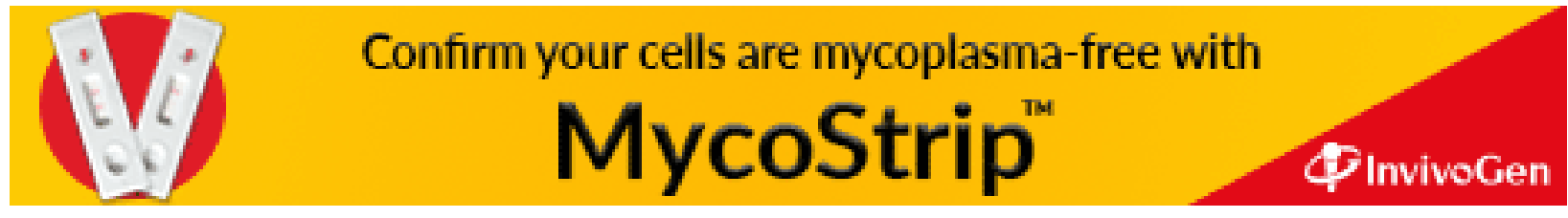

